\title{
CONSULTA DE ENFERMAGEM EM SAÚDE DA CRIANÇA - MODELO OPERACIONAL
}

\author{
Maria Jacyra de Campos Nogueira*
}

NOGUEIRA, M. J. de C. Consulta de enfermagem em saúde da criança modelo operacional. Rev. Esc. Enf. USP, São Paulo, 14(1):29-49, 1980.

Este trabalho apresenta um modelo para a consulta de enfermagem referente à criança menor de um ano e vem sendo usado, por nós, há alguns anos, no ensino de campo da Habitação em Enfermagem de Saúde Pública da Escola de Enfermagem da Universidade de Sâo Paulo.

\section{INTRODUÇĀO}

O estágio sócio-econômico em que o País se encontra, aliado aos esforços do Governo para impulsionar o desenvolvimento, neste setor, estão exigindo a participação mais efetiva do setor saúde e, conseqüentemente, da enfermagem ${ }^{2}$.

Uma das metas do II Plano Nacional de Desenvolvimento ${ }^{4}$ inclui a assistência sanitária a $90 \%$ da população. $O$ grupo materno-infantil ${ }^{3}$, que representa uma parcela ponderável da população $(70,98 \%)$, é o grupo prioritário para a assistência sanitária, por se caracterizar, também, por condições bio-psico-sociais que o tornam o mais vulnerável aos riscos de adoecer e morrer.

Em São Paulo, a mortalidade infantil 3 é de 83,8 por mil nascidos vivos. Entre as principais causas de óbito encontram-se as doenças infecciosas destacando-se, como causas mais frequientes, as gastro-enterites, doenças respiratórias, sarampo, coqueluche, tétano, difteria e tuberculose, sendo a desnutrição a causa básica de morte, para a maioria delas.

O estudo dos indicadores de saúde leva à conclusão de que, no Brasil, figuram, entre outros fatos, no grupo infantil:

- as taxas de mortalidade e morbidade são muito altas e, em relação aos óbitos totais, há elevada proporção de óbitos de menores de um ano;

— há predominância de óbitos, neste grupo etário, por causas evitáveis.

Com relação aos recursos existentes ${ }^{3}$ para assistir a essa população, verifica-se, entre outros fatos, os seguintes:

- a distribuição geográfica e populacional é inadequada;

- Professor Assistente Doutor da Disciplina Enfermagem Preventiva e Comunitária da EEUSP. 
- são excessivas as internações hospitalares conseqüentes da insuficiência da rede ambulatorial, agravada pela quase inexistência de integração ambulatório-hospital-comunidade;

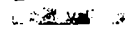

- há ausência quase absoluta de programas e coordenação de unidades de prestação de serviço;

- há precariedade e má utilização de equipamento e instalações; ção;

- é baixa a proporção dos elementos da equipe de saúde, em relação à popula-

— há insuficiência de médicos especialistas na área materno-infantil.

Uma das metas propostas na V Conferência Nacional de Saúde ${ }^{3}$, para minimizar o problema da saúda da criança, foi o de estender a cobertura a $60 \%$ das menores de um ano.

Experiências realizadas em vários paises ${ }^{1}$ vêm demonstrando que a ampliação de cobertura tem sido alcançada mediante adequação de tecnologia simplificadła onde a enfermagem tem uma participação muito grande.

is ,...in

Dentre as atividades de enfermagem previstas no programa materno-infantil para o País ${ }^{3}$, estão o atendimento de enfermagem, a visitação domiciliária e a vacinação, todas realizadas por pessoal auxiliar de enfermagem (visitadora, auxiliar de enfermagem, técnico de enfermagem e atendente). Está prevista, também, pelo Ministério de Saúde ${ }^{2}$, através da Divisão Nacional de Organização Sanitária, a consulta de enfermagem, como uma atribuição da enfermeira em nivel local.

Com base no programa materno-infantil para o País ${ }^{3}$, o presente trabalho tem como objetivo fornecer alguns subsídios para operacionalizar a atuação da enfermagem em ambulatórios e centros de saúde, através da apresentação de um modelo para a consulta de enfermagem em saúde da criança. Esse modelo que vem sendo usado na Escola de Enfermagem da Universidade de São Paulo, durante o ensino de campo do Habilitação em Enfermagem de Saúde Pública há vários anos ${ }^{6}$, tem sido modificado, principalmente no que diz respeito ao sistema de registro de dados. Apresentaremos, aqui, apenas aquele para registro de dados da consulta referente à criança menor de um ano, pois a nossa experiência tem sido maior com essa faixa etária e porque não haveria espaço suficiente para publicação dos modelos referentes às outras idades.

\section{MODELO OPERACIONAL PARA EXECUTAR A CONSULTA DE ENFERMAGEM REFERENTE A CRIANÇA MENOR DE UM ANO}

Para que a consulta de enfermagem tenha bom rendimento e atinja seus objetivos a enfermeira necessita, de acordo com nossa experiência, usar uma técnica sistematizada.

Essa técnica sistematizada é composta de fases seqüênciais (ações componentes) que estão, resumidamente, expostas no esquema a seguir. 
Fases ou ações componentes da consulta de enfermagem referente à criança Fases ou ações componentes da consulta de enfermagem referente à criança

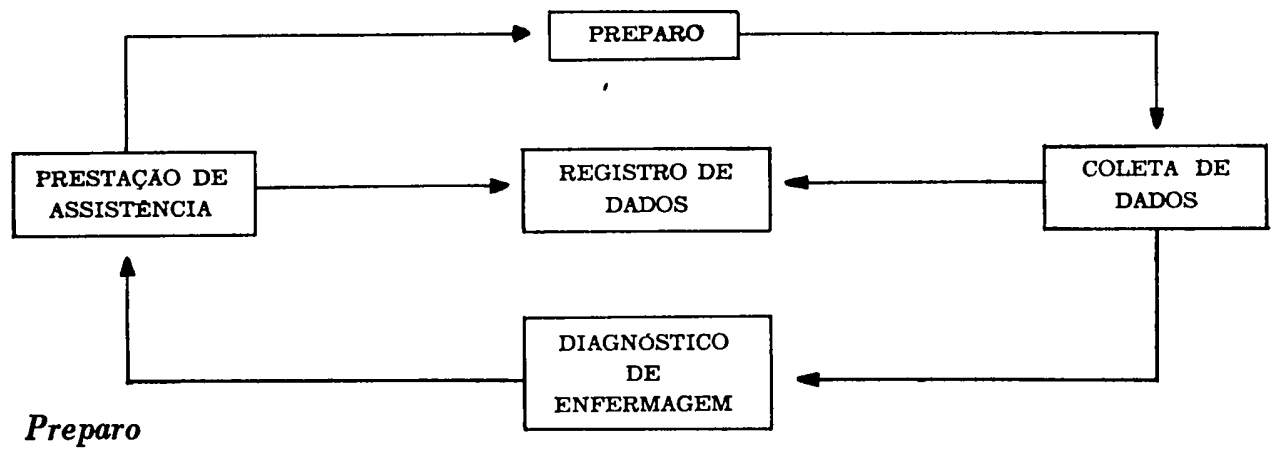

Antes de iniciar a consulta, verifica-se se o ambiente está adequado e o material em ordem e à mão.

A sala para a consulta deve ser clara, se possível com isolamento acústico e, de preferência iluminada com luz natural, para facilitar o exame físico da criança. Deve ter pia com água corrente, sabão e toalha de papel, para higiene das mãos. ".. 0 material mínimo, nessa sala, é:

- mobiliário: divã de exames, escrivaninha e cadeiras para acomodar a enfermeira e os clientes;

- material para o exame da criança: termômetro, balança infantil, abaixador de língua descartável, material para testar o desenvolvimento motor (chocalho, chupeta, cubos de madeira, copo, xícara, lápis, papel, etc.) lanterna, fita métrica, papel para forrar o divã e a balança;

- material para o ensino de pais (folhetos e outros impressos do serviço como receitas de mamadeira, sopa, etc.);

- manual de normas e procedimentos técnicos e administrativos do serviço.

Antes de iniciar a consulta, a enfermeira deve ler o prontuário da criança para se certificar dos dados já registrados que, por ventura existam.

\section{Coleta de dados}

A coleta de dados sobre a criança tem sido feita por nós através do seu histórico (entrevista), da medição de temperatura, peso, altura e perímetro cefálico e de um exame físico sumário.

Resumidamente, os dados que até o momento temos levantado, através da entrevista, são: condiçōes sócio-sanitárias da família (quando o serviço não tem esses dados registrados em uma ficha familiar), condiçôes de saúde pregressas e atuais da criança e dos familiares, hábitos de vida e aspectos gerais do desenvolvimento físico-psico-motor da criança. 
Para essa coleta de dados, instituimos uma seqüência lógica que visa ganhar tempo e não expor muito a criança e que está descrita, detalhadamente, nas instruções para a consulta e para registro de dados (Anexo II).

Á medida que os dados são colhidos ,eles têm sido anotados na "Ficha de Assistência de Enfermagem" (Anexo I), que também tem uma seqüência lógica, e com apresentação que visa facilitar a coleta de dados e o seu registro.

\section{Diagnóstico de enfermagem}

O diagnóstico de enfermagem, em uma consulta que deve ter rendimento muito grande, pois senão perderia os objetivos de aumentar a cobertura, deve ser feita imediatamente à coleta de dados.

Para nós, ele tem sido um pouco diferente do preconizado por HORTA 5 e que, no momento, está em uso em alguns hospitais de São Paulo, pois, até o momento, não conseguimos adaptá-lo para a assistência ambulatorial, devido à necessidade de encurtar o tempo de permanência do cliente, nesses serviços. Atualmente tem-se constituído de uma rápida avaliação da dependência dos pais ou responsáveis pela criança, em relação a alguns itens que representam suas necessidades, dentro da família e da comunidade em que vive (item 4 da Ficha de Assistência de Enfermagem: 1.a consulta - Anexo I) para, em seguida, levar às ações de fazer, orientar e encaminhar (momentâneas) ou de supervisionar (remotas).

\section{Prestação de assistência e registro de dados}

Esta fase, pela nossa experiência, tem sido muito mais relacionada a orientações e encaminhamentos. Com relação às orientações, como geralmente não se têm condições, em uma consulta, de orientar tudo o que os pais ou os responsáveis pela criança têm necessidade, ou fazer todos os encaminhamentos possíveis e necessários, têm-se elegido, apenas, os tópicos prioritários, deixando os outros para as próximas oportunidades. Toda a orientação, ainda, tem sido acompanhada de uma prescrição, por escrito (quando alguém da família sabe ler), que é entregue aos pais ou responsáveis pela criança, contendo o nome, a data e a assinatura da enfermeira.

\section{CONCLUSÕES}

O modelo apresentado tem alcançado, até o momento, suas finalidades, isto é, a de fornecer a prestação de assistência global à criança menor de um ano, em ambulatórios e centros de saúde, com o maior rendimento possível. Há necessidade, entretanto, de que ele continue a ser testado, e de que outros modelos sejam propostos e testados, para que a enfermagem brasileira tenha, em um futuro próximo, padröes de assistência mais adequados.

NOGUEIRA, M. J. de C. A model of nursing consultation in child health. Rev. Esc. Enf. USP, São Paulo, 14(1):29-49, 1980.

This work presents a model of nursing consultation for use in the assistance of infants (up to one year). It is being used in field teaching of Public Health Nursing, at the School of Nursing, University of São Paulo, Brasil. 


\section{REFERENCIAS BIBLIOGRAFICAS}

1. ADAMI, N. P. Experiências sobre a atuação de enfermagem na atenção primária de saúde. Ent. Novas Dimens., São Paulo, 4(4): 212-22, jul./ago. 1978.

2. BRASIL. Ministério da Saúde. Modelo geral de enfermagem. Brasília, 1977.

3. BRASII. Ministério da Saúde. Conferência nacional de saúde, 5. ${ }^{2}$. Programa materno-infantil. Brasilia, 1975. V.2.

4. BRASIL. Plano nacional de desenvolvimento para 1975/79. 2. ${ }^{\circ}$ Diário Oficial, Brasília, 6 dez. 1979. Suplemento n. 235.

5. HORTA, W. de A. Diagnóstico de enfermagem - representação gráfica. Enf. Novas Dimens., São Paulo, 3(2): 75-7, mar./abr., 1977.

6. NOGUEIRA, M. J. de C. Uma experiência com consultas de enfermagem à criança. Rev. Bras. Enf., Brasilia, 30(3): 294-306, jul./set., 1979.

\section{BIBLIOGRaFIAS CONSULTADAS}

1. BASTOS, N. C. B. Educação sanitária. Rio de Janeiro, FSESP, 1963.

2. BLAKE, F. G. \& WAECHTER, E. H. Enfermagem pediátrica. 9. ed. Rio de Janeiro, Interamericana, 1977. $764 \mathrm{p}$.

3. BROWN, M. S. \& MURPHY, M. A. Ambulatory pediatrics for nurses. New York, McGraw.Hill, 1975. $468 \mathrm{p}$.

4. CONCEIÇAO, J. A. N. et alii. Modelo para o atendimetno global à criança em um hospital escola. Rev. Saúde públ., São Paulo, 8(4): 341-57, dez. 1974.

5. GERBER. Alimentos Infantis. Desenvolvimento pôndero-estatural. São Paulo, Gerber, 1979. s.d.

6. MORLEY, D. Prioridades en la salud Infantil. México, Pax-México, 1977. $414 \mathrm{p}$.

7. NOGUEIrA, M. J. C. et alii. Manual para o ensino de Enfermagem de Saúde Pública. São Paulo, Sociedade Beneficente São Camilo, 1978. $181 \mathrm{p}$.

8. SANA, J. M. \& JUDGE, R. D. Métodos para el examen físico en la pratica de enfermeria. Washington, OPAS, 1977. 434 p. 


\section{ANEXO I}

\section{FICHA DE ASSISTENCIA DE ENFERMAGEM}

(Saúde da Criança $-1 .^{a}$ consulta)

\section{HISTORICO}

\section{1. - IDENTIFICAÇAO}

Nome

N. ${ }^{\circ}$ de inscrição

Data de nascimento

Sexo

Data de abertura da ficha

Filiação: pai

mãe

Endereço:

1.2 - MOTIVO DA $10^{\mathrm{a}}$ DEMANDA AO SERVIÇO

\section{3 - DADOS SOCIO-SANITARIOS DA FAMILIA}

1.3.1 - condiçōes sócio-econômicas:

- n..$^{\circ}$ de pessoas na família: adultos ....... crianças

- renda familiar

- orçamento familiar: alimentação(\$)

— instrução: pai mãe

- ocupação: pai mãe

- previdência social e outros recursos

1.3.2 - habitação: própria ( ) alugada ( ) cedida ( ) outras

- unifamiliar ( ) coletiva ( ) n. ${ }^{\circ}$ de famílias

- tipo de construção

- relação pessoal/cômodo

- relação pessoal/cama

- procedência da água

- destino do lixo

- destino dos dejetos

- outras características

1.4 - CONDIÇOES DE SAUDE DA CRIANÇA (menor de um ano)

1.4.1 - gestação: pré-natal ( ) local ........ medicamentos tempo de gestação intercorrências

1.4.2 - parto: tipo . local assistência peso ao nascer altura chorou logo ( ) cianose ( ) reanimação ( ) intercorrências neonatais

1.4 .3 - desenvolvimento: sustentou a cabeça ....... sentou-se $1 .^{\circ}$ dente controle dos esfíncteres 
1.4.4 - antecedentes mórbidos:

\begin{tabular}{l|l|l|l|l}
\hline data & doença & local & atendimento & conduta \\
\hline & & & & \\
\hline & & & & \\
\hline & & & & \\
\hline & & & & \\
\hline & & & & \\
\hline
\end{tabular}

1.4.5 - antecedentes familiares e hereditários:

\begin{tabular}{l|l|l|l}
\hline tipo & observações & tipo & observações \\
\hline neoplasia & & alcoolismo & \\
\hline $\begin{array}{l}\text { doença cárdio- } \\
\text { vascular }\end{array}$ & & alergia & \\
\hline diabetes & & tuberculose & \\
\hline sífilis & & doença mental & \\
\hline hanseníase & & outros & \\
\hline
\end{tabular}

1.4.6 - imunizações:

\begin{tabular}{l|l|l}
\hline tipo & data de aplicação & reações \\
\hline B.C.G. & & \\
\hline Tríplice (C.D.T.) & & \\
\hline Antivaliólica & & \\
\hline Sarampo & & \\
\hline Dupla (D.T.) & & \\
\hline Antivariólica & & \\
\hline Sabin & & \\
\hline Soro & & \\
\hline Outras & & \\
\hline
\end{tabular}

1.4.7 - situação alimentar: alimentação natural até:

intercorrências alimentares

— alimentação atual:

- aleitamento natural ( ) limpeza dos seios

n. ${ }^{\circ}$ de mamadas/dia ............. intervalo

técnica de administração 
- aleitamento artificial ( ) fórmula láctea

desinfecção da mamadeira

técnica de administração

outras características

- geral ( ) leite e derivados carnes e ovos hortaliças

frutas outros

( ) quantidade/dia

( ) quantidade/dia

( ) quantidade/dia

( ) quantidade/dia

- hidratação:

- vitaminas sintéticas:

1.4.8 - funcionamento dos aparelhos, sistemas e órgãos:

- geral (peso, atividade, apetite, etc.)

— intercorrências (febre, medicação, etc.)

- olhos (visão, secreções, lacrimejamento, etc.)

- ouvidos (audição, secreção, dor, etc.)

- dentes (n. ${ }^{\circ}$, estado de conservação, etc.)

- garganta (infecções repetidas, mau hálito, etc.)

- infecções das vias aéreas superiores (coriza, frequiência, etc.)

- cárdio-respiratório (tosse, "chiado", cianose, falta de ar, frequiência, etc.)

- gastro-intestinal (cor, jato, volume, freqüência)

- gênito-urinário (corrimento, prurido, menarca, etc.)

- extremidades e coluna (edemas, paralisias, sequielas, reumatismo, etc.)

- sistema nervoso e psiquismo . (couvulsão, desmaio, perda de fôlego, comportamento, etc.)

- observações:

1.4.9 - choro:

(tipo, horário, tipo de atendimento, etc.)

1.4.10-asseio corporal:

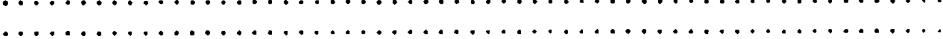

(couro cabeludo, banho, genitais, dentes, mãos, etc.)

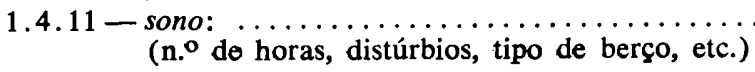

1.4.12-exercícios e vida ao ar livre: (para idade, frequiência, etc.)

1.4 .13 - recreação: (para idade, frequiência ,etc.)

1.4.14-vida efetiva $e$ social: (relacionamento com os pais, amigos, métodos disciplinares, etc.) 
1.4.15 - controle médico periódico:

(periodicidade, causas, local de atendimento, etc.)

Observações:

\section{5 - RESUMO DO DESENVOLVIMENTO (até 12 meses)}

\begin{tabular}{|c|c|c|c|c|c|}
\hline $\begin{array}{l}\text { idade aproximada em } \\
\text { que iniciou } \\
\text { principais } \\
\text { modificações de } \\
\text { acordo com a idade }\end{array}$ & 1 mês & 3 meses & 6 meses & 9 meses & 12 meses \\
\hline $\begin{array}{l}1 \text { mês } \\
\text { - agita mão cerradas } \\
\text { - não segura objetos } \\
\text { - fixa momentaneamente objetos e rostos } \\
\text { - firma a cabeça } \\
\text { - reflexo de Moro ativo } \\
\text { - reflexo de preensão e sucção } \\
\text { - responde a sons altos }\end{array}$ & & & & & \\
\hline $\begin{array}{l}3 \text { meses } \\
\text { - esboça contacto com chocalho } \\
\text { - levanta cabeça e tórax } \\
\text { - brinca com as mãos } \\
\text { - ri alto } \\
\text { - riso social } \\
\text { - arrulha e balbucia } \\
\text { - segue a pessoa com a cabeça } \\
\text { - reconhece a mãe }\end{array}$ & & & & & \\
\hline $\begin{array}{l}6 \text { meses } \\
\text { - senta sozinho } \\
\text { - pega brinquedos } \\
\text { - balbucia "m-m" quando chora } \\
\text { - levanta uma xícara } \\
\text { - responde alegre ao espelho } \\
\text { - começa a reconhecer estranhos } \\
\text { - diz "não-não" e arrulha } \\
\text { - primeiros dentes }\end{array}$ & & & & & \\
\hline $\begin{array}{l}9 \text { meses } \\
\text { - engatinha } \\
\text { - segura sozinho a mamadeira } \\
\text { - bebe em xícara com ajuda } \\
\text { - começa hábitos regulares de eliminação } \\
\text { - fica em pé com ajuda } \\
\text { - diz "dá-dá" ou eqüivalente } \\
\text { - vocaliza com os brinquedos } \\
\text { - procura quando sozinho }\end{array}$ & & & & & \\
\hline $\begin{array}{l}12 \text { meses } \\
\text { - vira páginas de um livro } \\
\text { - rabisca no papel } \\
\text { - fica em pé sozinho } \\
\text { - circula em volta dos móveis } \\
\text { - inicia domínio las mãos } \\
\text { - usa colher na alimentação } \\
\text { - empilha dois cubos } \\
\text { - fala "papa", "mama", "dá" } \\
\text { - ajuda no vestir } \\
\text { - come com os dedos }\end{array}$ & & & & & \\
\hline
\end{tabular}


2. EXAME FISICO-SUMARIO

2.1 - temperatura:

2.2 - aparência geral: $\begin{aligned} \text { - } & \text { tranquilo } \\ & \text { - calmo }\end{aligned}$

- indisposto

- agitado

- irritado

( )

( )

- outras características

2.3 - vestuário: de acordo com a temperatura ( ) não de acordo ( ) Limpo ( ) sujo (

2.4 - pele: - limpa ( ) suja ( ) corada ( ) pálila ( ) ictérica ( )

- lesões ( ) tipo

- outras características

2.5. - couro cabeludo - limpos ( ) sujos ( ) lesões ( ) tipo e cabelos: - outras características

2.6 - cabeça: fontanela ausente ( ) presente ( ) depressão normal ( ) deprimida ( ) abaulada( )

2.7 - mucosas: - coradas ( ) descoradas ( ) lesões ( ) tipo

- outras características

2.8 - pescoço, tronco: - gânglios palpáveis $($ ) não palpáveis $($ ) turgor firme $($ )

- frouxo ( ) abdomem normal ( ) distendido ( ) encovado ( ) - outras características

2.9 - genitais: - limpos ( ) sujos ( ) outras características

2.10 - cavidade oral: - limpa ( ) suja ( ) dentição normal ( ) retardada ( )

- outras características

Observações: 
3 - GRÁFICOS DE CRESCIMENTO

(meninos)

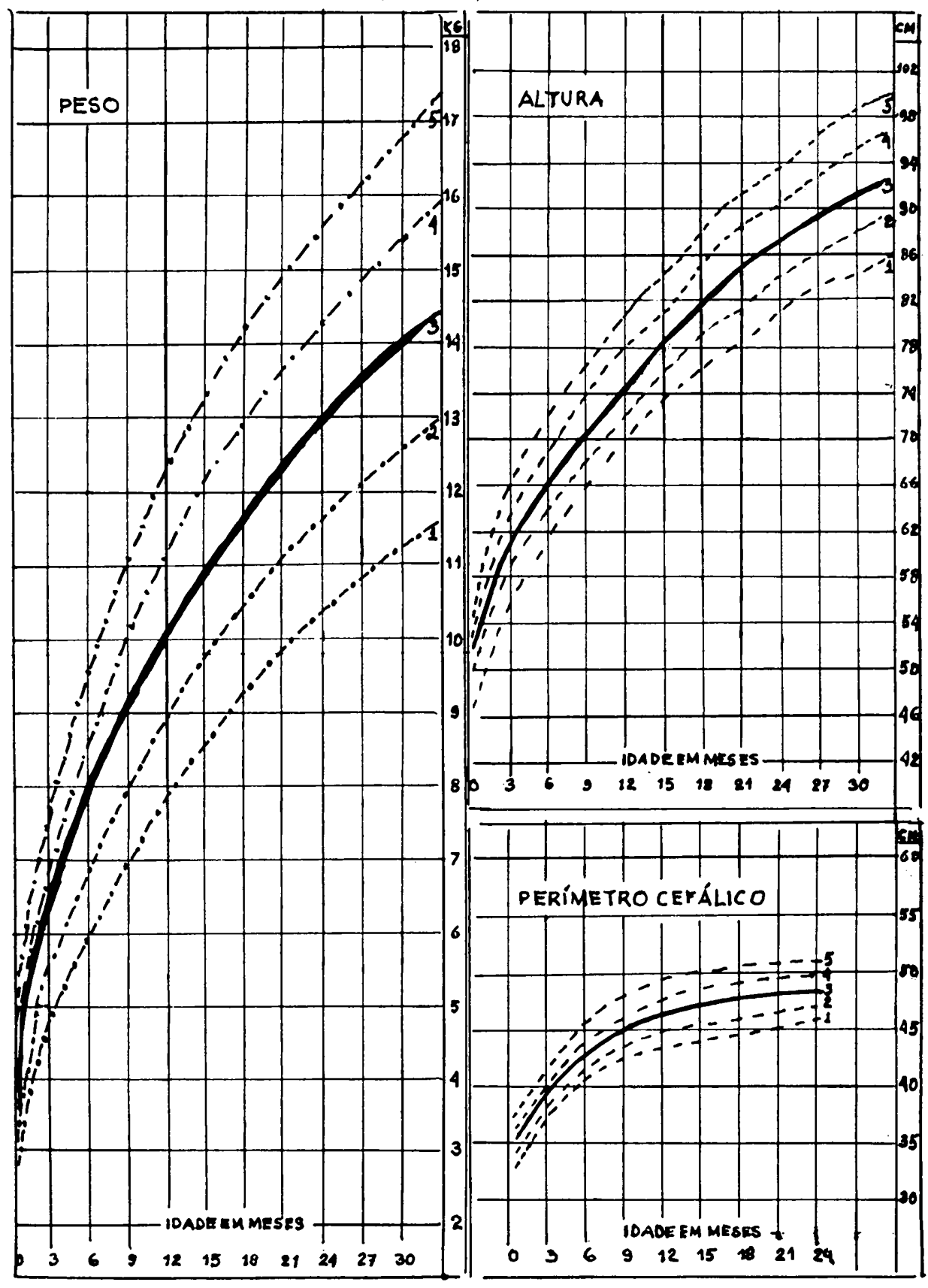

Adaptado de: GERBER ALIMENTOS INFANTIS. Gráficos de crescimento: 
3 - GRĀFICOS DE CRESCIMENTO

(meninas)

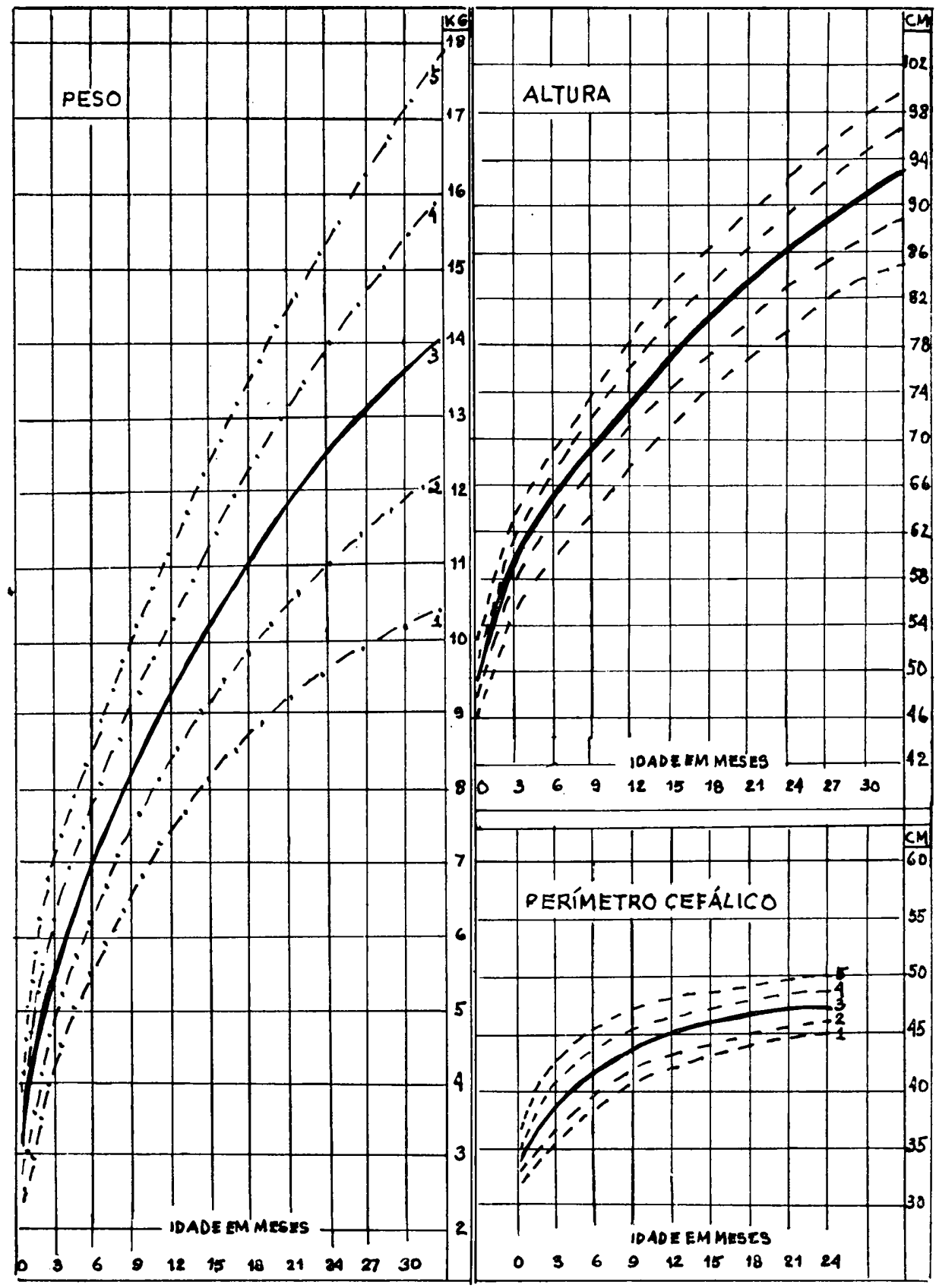

Adaptado de: CERBER ALIMENTOS INFANTIS. Gräficos de crescimento. 


\begin{tabular}{|c|c|c|c|c|c|c|c|c|c|c|c|c|}
\hline \multirow{2}{*}{$\begin{array}{l}\text { NECESSIDADES } \\
\text { RELACIONADAS A }\end{array}$} & \multicolumn{3}{|c|}{ Data } & \multicolumn{3}{|c|}{ Data } & \multicolumn{3}{|c|}{ Data } & \multicolumn{3}{|c|}{ Data } \\
\hline & D & $\mathbf{I}$ & Ação & D & I & Ação & D) & I & Ação & $\bar{D}$ & $\mathbf{I}$ & Ação \\
\hline \multicolumn{13}{|l|}{$\begin{array}{l}\text { 1. Condições sócio-econômicas } \\
\text { e sanitárias da família }\end{array}$} \\
\hline \multicolumn{13}{|l|}{ - habitação } \\
\hline \multicolumn{13}{|l|}{ - recursos da comunidade } \\
\hline \multicolumn{13}{|l|}{ - orçamento e renda } \\
\hline \multicolumn{13}{|l|}{ 2. Alimentação } \\
\hline \multicolumn{13}{|l|}{ 3. Hidratação } \\
\hline \multicolumn{13}{|l|}{$\begin{array}{l}\text { 4. Funcionamento dos apare- } \\
\text { lhos }\end{array}$} \\
\hline \multicolumn{13}{|l|}{ - gastro-intestinal } \\
\hline \multicolumn{13}{|l|}{ — órgãos dos sentidos } \\
\hline \multicolumn{13}{|l|}{ - dentes } \\
\hline \multicolumn{13}{|l|}{ — cárdio-respiratório } \\
\hline \multicolumn{13}{|l|}{$\begin{array}{c}\text { - sistema nervoso e psi- } \\
\text { quismo }\end{array}$} \\
\hline \multicolumn{13}{|l|}{ - gênito-urinário } \\
\hline \multicolumn{13}{|l|}{$\begin{array}{l}\text { 5. Desenvolvimento psicomo- } \\
\text { tor }\end{array}$} \\
\hline \multicolumn{13}{|l|}{ 6. Imunizações } \\
\hline \multicolumn{13}{|l|}{ 7. Asseio corporal } \\
\hline \multicolumn{13}{|l|}{ 8. Sono } \\
\hline \multicolumn{13}{|l|}{ 9. Exercício e vida ao ar livre } \\
\hline \multicolumn{13}{|l|}{ 10. Recreação } \\
\hline 11. Vida afetiva e social & & & & & & & & & & & & \\
\hline
\end{tabular}

LEGENDA: $\left.\begin{array}{l}\mathbf{D}=\text { depenlência } \\ \mathbf{I}=\text { independência }\end{array}\right\} \quad$ grau de dependência de enfermagem

$F=$ fazer

$\mathrm{O}=$ orientar

$\mathbf{E}=$ encaminhar

$\mathbf{S}=$ supervisionar

ações de enfermagem

5 - REgISTRO DA ASSISTENCIA PRESTADA NA PRIMEIRA CONSULTA 


\section{FICHA DE ASSISTENCIA DE ENFERMAGEM}

(saúde da criança - consultas subsequientes)

Nome:

N. ${ }^{\circ}$ de inscrição:

\section{1 - HISTORICO}

1.1 - Situação alimentar:

intercorrências alimentares:

- alimentação atual:

aleitamento natural ( ) limpeza dos seios

n. ${ }^{\circ}$ de mamadas/dia

intervalo

técnica de administração

- aleitametno artificial ( ) fórmula láctea

desinfecção da mamadeira

técnica de administração

outras características

- geral ( ) leite e derivados ( ) quantidade/dia

carnes e ovos ( ) quantidade/dia

hortaliças ( ) quantidade/dia outros

( ) quantidade/dia

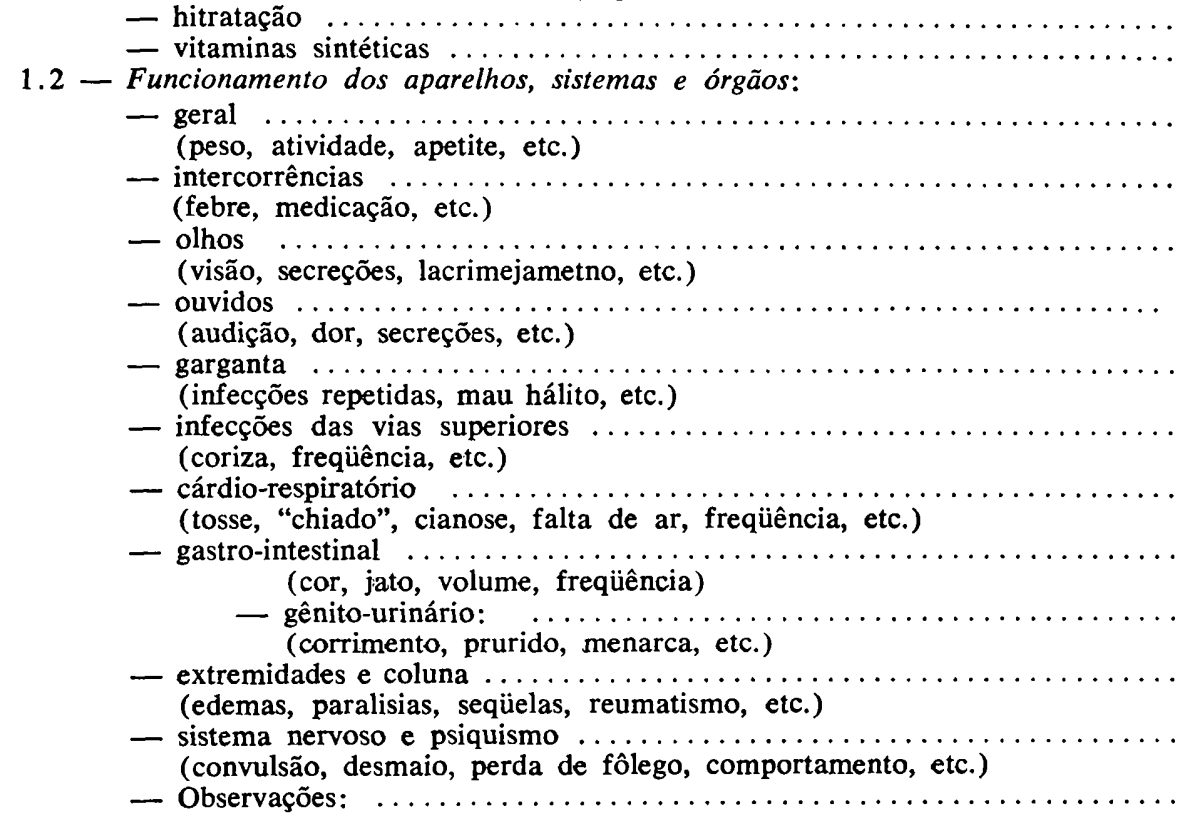

- hitratação

1.3 - Choro:

(tipo, horário, tipo de atendimento, etc.)

1.4 - Asseio corporal:

(couro cabeludo, banho, genitais, dentes, mãos, etc.)

1.5 - Sono:

(n. ${ }^{\circ}$ de horas, distúrbios, tipo de berço ,etc.) 
1.6 - Exercícios e vida ao ar livre: (para idade, freqüência, etc.)

1.7 - Recreação: (para idade, freqüência, etc.)

1.8 - Vida afetiva e social: (relacionamento com os pais, amigos, métodos disciplinares, etc.)

Observaçöes:

\section{$2-E X A M E$ FISICO SUMARIO}

2.1 - temperatura .......... peso (g) altura

2.2 - aparência geral: - bem disposto

( )
( )

indisposto (cm)

- calmo

- tranquilo

- outras características:

2.3 - vestuário: de acordo com a temperatura ( ) não de acordo ( ) limpo ( ) sujo ( )

2.4 - pele: - limpa ( ) suja ( ) corada ( ) pálida ( ) ictérica ( )

$$
\text { - lesões ( ) tipo ..... }
$$

2.5 - couro cabeludo: - limpos ( ) sujos ( ) lesões ( ) tipo e cabelos

- outras características

2.6 - cabeça: - fontanela ausente ( ) presente ( ) depressão normal ( )

— deprimida ( ) abaulada ( )

2.7 - mucosas: - coradas ( ) descoradas ( ) lesões ( ) tipo

2.8 - pescoço, tronco: - gânglios palpáveis ( ) não palpáveis ( ) turgor firme ( ) - frouxo ( ) abdomem normal ( ) distendido ( ) encovado ( )

- outras características

2.8 - genitais: - limpos ( ) sujos ( ) outras características

2.10 - cavidade oral: - limpa ( ) suja ( ) dentição normal ( ) retardada ( )

- outras características

Observações:

3 - REGISTRO DA ASSISTENCIA PRESTADA NAS CONSULTAS SUBSEQUENTES 
(Ficha de continuação)

Nome:

N. ${ }^{\circ}$

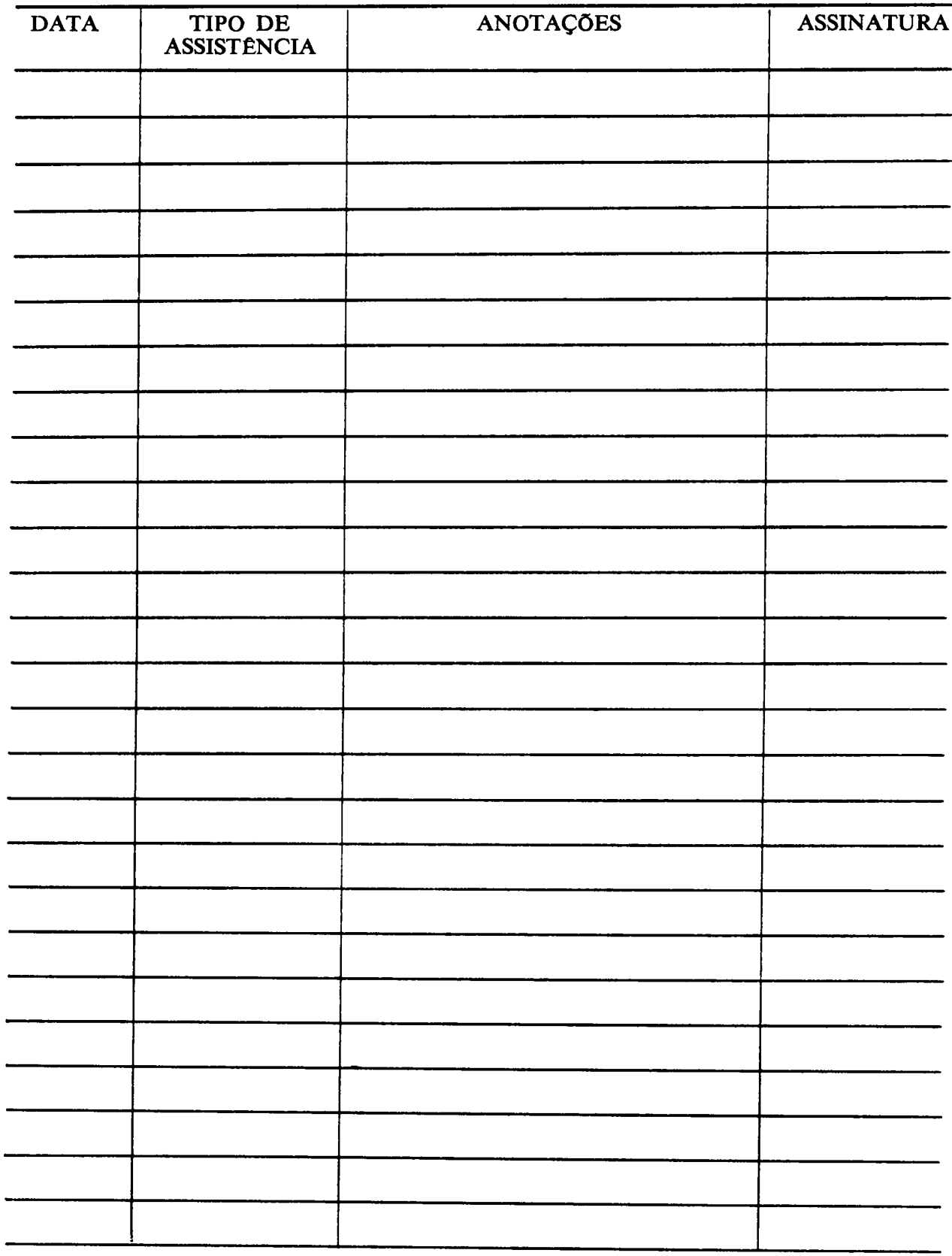



PARA O REGISTRO DE DADOS NA "FICHA DE ASSISTENCLA DE ENFERMAGEM"

PASSOS

1 - "Rapport"

2 - Medição de temperatura

3 - Entrevista

\section{CUIDADOS}

- Coloque a criança e a mãe à vontade, sentadas confortavelmente.

- Apresente-se, explique as perguntas que irá fazer, o motivo das mesmas, o tipo de orientações que irá dar e na importância.

- Ofereça um brinquedo para a criança que já consegue segurá-lo, a fim de que ela se distraia.

- Coloque o termômetro durante 7 minutos, enquanto inicia a entrevista. Terminado o tempo,anote o resultado no item 2.1 , da ficha de $10^{\mathrm{a}}$ consulta.

- Esqueça seus preconceitos e respeite os valores do seu entrevistado. Só oriente contra uma prática de saúde, usada para acriança, se ela for comprovadamente nociva. Explique sempre os porquês das orientações, principalmente daquelas que quem cuida da criança deve passar a seguir.

- Adapte a orientação às condições sócio-econômicas-culturais da família e à escolaridade de quem cuida da criança.

- Tente compreender os problemas sentidos pelo seu entrevistado, mesmo que, diretamente, não seja um problema da criança; Dê-lhe atenção, pois o entrevistado ficará mais aliviado de suas próprias tensões e ouvirá melhor a orientação da enfermeira. Além disso, o problema pode, indiretamente, estar afetando a criança.

- Tente separar as informações objetivas das subjetivas expostas pelo entrevistado. Às vezes, os problemas relatalos são dos pais e não da criança, ou então os fatos não são como estão sendo expostos.

- Mostre apenas os caminhos, não imponha soluções, pois elas podem não ser as melhores naquele caso.

- Faça uma pergunta por vez ou trate de um assunto, por vez, até esgotá-lo, ante de passar para outro. Faça as perguntas claras, objetivas e curtas, tentando não induzir as respostas. Use linguagem compreensível ao entrevistado.

- Registre os dados da entrevista, à medida que os vai colhendo. Tenha cuidado, entretanto, de não ficar todo o tempo olhando para a ficha e para as anotações, para não prejudicar sua relação com o entrevistado. Explique o sigilo das anotações.

- Esteja atenta às expressões fisionômicas e ao relacionamento entre o acompanhante e a criança, observando o cuidado do primeiro em relação a ela.

- Registre os dados da entrevista no item 1 da ficha de $1 .^{a}$ consulta, para a primeira consulta, ou primeira e segunda, para as consultas subseqüentes, tendo o cuidado de não fazer abreviações desconhecidas, usar letra legível, fazer juízo de valores. Prefira usar as mesmas palavras ditas pelo informante, colocando-as entre aspas. Escreva à tinta todos os dados, com exceção do endereço, que pode mudar. Não rasure o que já está registrado e, se forem necessários emendas, intercale - as com "digo", seguida da forma correta. 
- no item 1.1 - se houver necessidale, peça um documento (Registro de Nascimento da criança) para que o nome seja registrado de forma correta;

- no item 1.3.1 e 1.3.2 - só preencha se não houver, no serviço, ficha familiar com eses dados registrados.

- nos itens 1.4 .1 a 1.4 .5 - use terminologia popular para substituir alguns termos que porventura não sejam conhecido pelo entrevistado, como por exemplo: cianose ("ficou roxinho"), diabetes ("açúcar no sangue"), etc.;

- no item 1.4.4 - escreva a (as) época (s), se o informante não souber a (s) data (s) em que tenha ficado doente. Escreva, em local, o lugar onde adoeceu (por exemplo: domicílio, creche, casa do vizinho, dos avós, etc.); em atendimento, onde ou quem atendeu (por exemplo: farmácia, pronto socorro, benzedor, etc.) e em conduta, qual o tratamento a que a criança foi submetida (por exemplo, soro, antibiótico, chá caseiro, benzedura, etc.);

- no item 1.4.6 - peça ao acompanhante a "Caderneta de Vacinações"da criança: se ele não a tiver em mãos, peça para trazê-la na próxima vez. Copie os dados dela nas colunas desse item.

- no item 1.4.7 - coloque até que mês ou dia a criança recebeu o leite materno. Descreva, sucintamente, porque o mesmo não está sendo mais administrado, além de outros problemas alimentares que a criança apresentou no item intercorrências alimentares (por exemplo, mãe informa que "o leite secou", "a criança não aceitou", "teve que trabalhar", etc.). Faça um $\mathbf{X}$ após o aleitamento natural ou aleitamento artificial, conforme a informação; anote, nos dois, se o aleitamento for misto. Descreva, em poucas palavras, como é feita a limpeza dos seios (por exemplo, "com água e sabão", "com água fervida", "com água boricada", etc.); o número de mamadas por dia e por horários (por exemplo: 6-9-12-1518-22 ou 4-8-12-16-20, etc.); os intervalos (regulares irregulares, sem horário, etc.); a técnica de amamentar (por exemplo: "no colo, com eructação" ou "na cama, sem eructação", etc.) e a fórmula láctea usada (por exemplo: "Ninho 10\%, 150 gramas, deixa resto").

Em outras características, acrescente outras informações, tais como: "chora meia hora após as mamadas", "o buraco do bico da mamadeira é muito grande", "a mãe está com os seios rachados", etc.

$\mathrm{Na}$ alimentação geral, coloque um $\mathrm{X}$ no ailmento que o informante disser que a criança come e a quantidade, aproximada, por dia (por exemplo: " 2 vezes", "um prato fundo cheio", etc.). Em outros, marque: bolachas, café, balas, etc., anotando a quantidade aproximada. Quanto às vitaminas sintéticas tomadas pela criança, anote 0 nome do produto, a quantidade por dia e se foi ou não por indicação médica. Faça tudo igual quando se trata de consulta subseqüente, mas marque no item 1.1 do impresso para as consultas subsequientes.

- no item 1.4.8 - anote, do mesmo modo sucinto e de acordo com o que está escrito, entre parênteses, em baixo 
de cada sub-item.

- no item 1.4.9 a 1.4.15 - anote, do mesmo modo sucinto e de acordo com o que está escrito, entre parênteses, em baixo de cada item.

- no item 1.5 - vá perguntando ao informante a época aproximada em que a criança apresentou modificação psico-motoras listadas na coluna à esquerda. Coloque um $\mathrm{X}$ nas colunas correspondentes aos meses que mais se aproximam da informação. Caso seja entre os intervalos das épocas que aparecem no item, coloque esse $\mathrm{X}$ em cima da linha, no intervalo entre elas.

4 - Exame físico sumário
- Verifique se não há corrente de ar e, se houver, feche as janelas. Lave as mãos e esfregue-as para aquecê-las, antes de tocar na criança.

- Peça ao acompanhante para despir a criança, enquanto forra a balança com papel e verifica se ela está equilibrada (tarada).

- Pese a criança, tendo o cuidado de não deixá-la só na balança mas amparando-a, com a mão, sem tocar nela e na balança.

- Retire-a e leve-a para o divã de exames. Meça sua altura e perímetro cefálico, pedindo à mãe ou acompanhante que ajude a segurá-la.

- Anote peso, altura e perímetro cefálico, em um papel à parte.

- Começe o exame físico, observando a aparência geral e o vestuário da criança, passando a examiná-la, na seguinte ordem: pele, couro cabeludo, cabeça, mucosa ocular, pescoço, tronco, genitais. Deixe a cavidade oral para o fim, pedindo ao acompanhante que segure a criança virada para a luz. Aproveite enquanto a criança está no divã e faça os testes de desenvolvimento motor para aquelas modificações que o acompanhante não soube informar.

- Peça ao acompanrante para vestir a criança. Enquanto ele faz isso, registre os resultados da sua observação nos itens 2.1 a 2.10 , da ficha de $1 .^{\mathrm{a}}$ consulta, no caso da primeira consulta e, nos itens 2.1 a 2.10 da ficha de consultas subsequientes no caso das consultas subseqüentes, Passe o peso, a altura e o perímetro cefálico no gráfico do item 3 da ficha de $1 .^{\text {a }}$ consulta, que é específico para meninos ou meninas, da seguinte maneira: para se determinar em as condições de desenvolvimento pôndero-estatural de uma determinada criança, procede-se da seguinte maneira: traça-se uma linha vertical na posição equivalente à idade da criança, no momento da avaliação. Em seguida, uma linha horizontal, no ponto equivalente à medida em que se está efetuando (peso em quilos, altura em centímetros e perímetro cefálico também em centímetro). A intersecção dessas duas linhas, no gráfico, representará a posição relativa da criança quanto à "faixa de normalidade" para cada idade e para cada criança em particular. Em relação ao conceito dessa "faixa de normalidade", o seguinte critério pode ser sugerido: 1) ponto de intersecção localizado no traçado da Curva 3: o parâmetro analisado está exatamente na média esperada para a idade; 2) ponto de intersecção localizado 
no traçado da Curva 5: o parâmetro analisado corresponde ao limite máximo da normalidade para a idade; 3 ) ponto de intersecção localizado no traçado da Curva 1: o parâmetro analisado corresponde ao limite mínimo da normalidade para a idade; 4) ponto de intersecção localizado entre os traçados das Curvas 2 e 4: o parâmetro analisado está dentro dos limites rígidos da normalidade, para a idade; 5) ponto de intersecção localizado entre os traçados das Curvas 4 e 5: o parâmetro analisado está dentor dos limites aceitáveis da normalidade, seja na faixa superior (entre as curvas 4 e 5), seja na faixa inferior (entre as curvas 1 e 2) na normalidade; 6) ponto de intersecção localizado acima da Curva 5 ou abaixo da Curva 1: o parâmetro analisado está fora (acima ou abaixo) dos limites extremos da normalidade, para a idade.

Escreva, em observações, da ficha de $1 .^{\text {a }}$ consulta ou da ficha de consultas subseqüentes, os problemas que a criança apresentou, tais como por exemplo: assadura, fimose, amigdalas hiperemiadas, talco nos genitais, etc. Faça o mesmo em outras características, descrevendo sucintamente os problemas mais gerais.

5 - Cuidados, orientações e encaminhamento

\section{6 - Encerramento}

7 - Registro da assistência prestada
- Preste os cuidados necessários, ensinando o acompanhante a fazê-los (por exemplo, como fazer um curativo de umbigo, furar o bico da mamadeira, manter posição adequada para amamentar, etc.).

- Oriente a respeito dos assuntos prioritários e deixe os outros para os próximos retornos. Escreva a prescrição com letra legível, usando terminologia adequada, ao nível de instrução de quem vai cuidar da criança. Coloque no cabeçalho o nome da criança, e seu número de inscrição no serviço, e sua assinatura e data no final. Faça as receitas de mamadeira, sopa, etc., no caso de não ter material impresso, descrevendo todos os passos do preparo, assim como para as outras orientações. Faça os encaminhamentos, também por escrito, colocando sua assinatura e data em que foram feitos.

- Encerre a consulta, avaliando e resumindo as principais orientações e colocando o acompanhante à vontade para as perguntas que ainda tiver necessidade de fazer.

- Após a saída da criança, registre o diagnóstico de enfermagem no item 4 , da ficha de $1 .^{a}$ consulta, da seguinte maneira:

- registre a data em que está fazendo a avaliação;

- avalie a dependência de enfermagem que a família ou quem cuida da criança tem, em relação às necessidades listadas na coluna à esquerda; marque, após essa avaliação, nas colunas de dependência (D) ou independência (I), com um $X$, aquelas necessidades avaliadas, de acordo com o seguinte critério: há independência, da enfermagem, quando a família ou quem cuida da criança não apresenta problema relacionado àquela necessidade, já presta assistência adequada à criança ou já está bem 
orientada a respeito; há dependência, quando apresenta algum problema relacionado àquela necessidade, não presta assistência adequada ou não está suficientemente bem orientada;

- coloque, na coluna ação, o que deve ser feito ou já foi feito com a criança durante a consulta, escrevendo um $\mathrm{F}, \mathrm{O}, \mathrm{E}$ ou $\mathrm{S}$, conforme a ação seja, respectivamente, fazer, orientar, encaminhar ou supervisionar.

- Anote, no item 5 da ficha de $1 .^{a}$ consulta, o que foi feito com a criança, caso se trate de primeira consulta no item 3 da ficha de consultas subseqüentes, o seguinte: outras informações e observações a respeito da criança ou da família e que não couberem nos itens anteriores; informações adicionais relatadas pelo acompanhante; orientações dadas e cuidados prestados; encaminhamentos feitos.

NOTA : a "Ficha de continuação" servirá, no prontuário, para registrar outras atividades que serão executadas, na assistência à criança, tais como: visitas domiciliárias, palestras para os pais, etc. 